\title{
Effect of Obesity on Left Ventricular Longitudinal Myocardial Strain by Speckle Tracking Echocardiography in Children and Adolescents
}

\author{
Ayşe Esin Kibar ${ }^{1}$, Feyza Ayşenur Pac ${ }^{2}$, İbrahim Ece ${ }^{3}$, Mehmet Burhan Oflaz ${ }^{4}$, \\ Şevket Ballı, ${ }^{5}$ Veysel Nejat Bas ${ }^{6}, Z_{\text {Zehra Aycan }}^{6}$
}

\author{
'Department of Pediatric Cardiology, Mersin Women's and Children's Hospital, Mersin, Turkey \\ ${ }^{2}$ Department of Pediatric Cardiology, Türkiye Yüksek İhtisas Training and Research Hospital, Ankara, Turkey \\ ${ }^{3}$ Department of Pediatric Cardiology, Yüzüncü Yll University Faculty of Medicine, Van, Turkey \\ ${ }^{4}$ Department of Pediatric Cardiology, Cumhuriyet University Faculty of Medicine, Sivas, Turkey \\ ${ }^{5}$ Department of Pediatric Cardiology, Balıkesir Hospital, Balıkesir, Turkey \\ ${ }^{6}$ Department of Pediatric Endocrinology, Dr Sami Ulus Obstetrics and Gynecology, Children's Health and Disease Training and Research Hospital, Ankara, Turkey
}

Background: Impaired subclinical ventricular function may contribute to the risk of cardiovascular disease in obesity.

Aims: The aim of this study was to determine the influence of obesity on left ventricular (LV) longitudinal myocardial function in normotensive obese children using two-dimensional (2D) speckle tracking echocardiography (STE).

Study Design: Case-control study.

Methods: Sixty normotensive obese children aged 1016 years (mean age, $13.9 \pm 2.3$ years) were compared with 50 normal-weight controls. Obese participants had a body mass index $(\mathrm{BMI}) \geq 95^{\text {th }}$ percentile. Regional strain/strain rate (SR) values were compared with left ventricular (LV) parameters. The correlation was studied by linear regression analysis.

Results: Obese subjects exhibited a significantly higher LV end-diastolic diameter, left atrium/aortic diameter ratio, and LV mass/index when compared to controls $(p<0.001)$. Left ventricular ejection fraction and regional systolic myocardial velocities were similar in the obese and control groups. By 2D STE, regional strain of both the septal wall (average strain:
$-16.0 \pm 3.9 \%$ vs $-21.9 \pm 2.4 \%, \mathrm{p}<0.001)$ and lateral wall (average strain: $-15.6 \pm 2.3 \%$ vs $-22.9 \pm 3.5 \%, p<0.001$ ); regional SR of both the septal wall (average SRsys: $-0.7 \pm 0.22 \mathrm{~s}^{-1}$ vs $\left.-1.3 \pm 0.32 \mathrm{~s}^{-1}, \mathrm{p}<0.001\right)$ and lateral wall (average SRsys: $-0.67 \pm 0.19 \mathrm{~s}^{-1}$ vs- $1.33 \pm 0.31 \mathrm{~s}^{-1}$, $\mathrm{p}<0.001$ ); regional $\mathrm{SR}_{\mathrm{E} / \mathrm{A}}$ of both the septal wall (average $\mathrm{SR}_{\mathrm{E} / \mathrm{A}}: 1.8 \pm 0.83$ vs. $2.2 \pm 0.91$, p: 0.004$)$ and lateral wall (average $\mathrm{SR}_{\mathrm{E} / \mathrm{A}}: 1.4 \pm 0.43$ vs. $2.4 \pm 1.21, \mathrm{p}<0.001$ ); and global strain $(-14.6 \pm 7.34 \%$ vs $-20.9 \pm 3.24 \%$, $\mathrm{p}<0.001$ ) were lower in the obese group compared with the controls. These strain imaging parameters appear to be related to the severity of obesity and can contribute to increased BMI. Left ventricular mass was found to be correlated with a decrease in global LV strain.

Conclusion: Our study showed that childhood obesity is associated with an alteration in the longitudinal LV function. Segmental analysis of the LV can provide subtle markers for the emergence of future obesityrelated cardiac disease.

Keywords: Childhood obesity, left ventricular function, strain, two-dimensional speckle tracking echocardiography

Address for Correspondence: Dr. Ayşe Esin Kibar, Department of Pediatric Cardiology, Mersin Women's and Children's Hospital, Mersin, Turkey Phone: +90 5325490965 e-mail: dreseresin@yahoo.com

Received: 24.09.2013 Accepted: 30.11.2014 • DOI: 10.5152/balkanmedj.2015.15136

Available at www.balkanmedicaljournal.org 
Childhood obesity is one of the most serious public health problems (1-3). Obesity and cardiac involvement has been reported frequently in the literature, but analysis of regional myocardial function in children by two-dimensional (2D) speckle tracking echocardiography (STE) is rarely documented (4-8).

Subclinical left ventricular dysfunction is an important finding in obese people and is an early sign of heart failure $(2,7)$. Moreover, it is also noted that developed subclinical cardiac effects in different studies reverse the process during weight loss (9-11, 12-13). In addition, 2D STE is a new and more sensitive echocardiographic modality, which allows the assess regional and myocardial function with strain and strain rate (SR) measurements $(11,13-15)$. These strain parameters are affected to a much lesser extent by cardiac rotation and passive cardiac motion $(2,11,16)$. Previous studies have demonstrated decreased regional myocardial function related to body mass index (BMI) by strain imaging studies $(7,8,11,13,17-20)$.

Apparent myocardial contractile dysfunction is rare, and also generally preserved reserve capacity with exercise in obese patients. Our reports have showed the effects of obesity on cardiac size, function, and subclinical myocardial damage in the pediatric age group. Study aims to evaluate, the effect of obesity on the risk of subclinical LV longitudinal myocardial dysfunction in normotensive obese children by 2D STE, which is an angle-independent and new technique for studying myocardial deformation. It may be important in determining the relationship between childhood obesity and cardiovascular risk factors in the preclinical stage.

\section{MATERIALS AND METHODS}

\section{Study groups and patient population}

This prospective and cross-sectional study in obese children was conducted in our hospital's Department of Pediatric Cardiology during the period from June 2010 to November 2011 . The study included 110 children aged $10-16$ years, including 60 obese children and 50 healthy children as the control group.

Overall, we studied 110 subjects divided into two groups as: (i) obese children (Group 1: $n=60$; mean age, 13.9 \pm 2.3 years) and (ii) control subjects (normal weight), comparable for age and sex, recruited from the community without family history of hypertension or obesity (Group 2: $n=50$; mean age, $13.2 \pm 1.8$ years $)$.

Obesity in children was defined as a BMI greater than the $95^{\text {th }}$ percentile for age and sex according to the reference values for the Turkish pediatric population (4). BMI of the patients was calculated using the equation: $\mathrm{BMI}=$ Body weight $(\mathrm{kg}) /$ Height $(\mathrm{m})^{2}$.
The research protocol was approved by the local ethical committee. All parents gave their written informed consent for participation in the study.

\section{Exclusion criteria}

This study excluded children with structural or functional cardiac abnormality, hypertension, the presence of sleep apnea, systemic diseases, history of medical treatment, or any secondary causes of obesity. Participants who refused echocardiography measurement, obese cases had poor image quality, and and blood sampling were also excluded.

\section{Clinical assessment}

Demographic details of age, gender, and blood pressure (BP) were derived standard measurements. Obese and healthy children exhibiting normal results were included in this study. The obese group underwent standard blood analyses (complete blood count, biochemistry, and thyroid function tests), BP measurement, chest X-ray, electrocardiography, and echocardiography. All measurements were performed by welltrained technicians. The anthropometric measurements were performed in the outpatient clinic. All of the measurements were repeated twice, and the average was used.

Arterial blood pressure (BP) was measured twice on the right arm after a 10 -minute ( $\mathrm{min}$ ) rest in the supine position in a quiet room using a calibrated sphygmomanometer, and the measurements were averaged. The $<90^{\text {th }}$ percentile of Systolic and diastolic blood pressure values for each age and gender were compared with the Turkish pediatric population (21). Hypertensive patients were excluded by history and measurement of BP, and ambulatory blood pressure measurements (ABPM) were taken.

Ambulatory blood pressure measurements (ABPM) normative data by 24-hour (h) systolic and 24-h diastolic BP were included ( $<90$ th percentile for age and sex). A Rozinn Ambulatory Blood Pressure (ABP) Recorder, RZ250 monitor (Day \& Night analysis, Glendale, New York, NY, USA) weighing $250 \mathrm{~g}$ (including batteries) was used for ABPM.

Determination of pubertal development was according to Marshall and Tanner and categorized into two groups (prepubertal: stage I, pubertal: stage $\geq 2$ ) (22).

\section{Biochemistry examination}

All cases in the obese group underwent standard blood analyses including complete blood count, biochemistry, and thyroid function tests. In all of the obese children, insulin and glucose levels were measured (after an overnight fast $>12 \mathrm{~h}$ ). Measurement of the concentration of glucose in the blood using the glucose-oxidase method by an autoanalyzer. Insulin levels were measured with an immunoradiometric assay. 
HOMA-IR (homeostatic model assessment of insulin resistance) was calculated using the formula given below. HOMAIR cut-off values for insulin resistance during childhood were calculated to be 2.5 (22).

HOMA-IR = fasting insulin $(\mathrm{mIU} / \mathrm{mL}) \times$ fasting blood glucose* (mmol/L) / 22.5

$(*$ Blood glucose: $\mathrm{mg} / \mathrm{dL} / 18=\mathrm{mmol} / \mathrm{L})$

\section{Echocardiographic measurements}

Left ventricular functions were investigated in a silent setting in the pediatric cardiology outpatient clinic. All subjects were evaluated by the same observer in the left lateral position. After the subject had been resting for $10 \mathrm{~min}$. Echocardiographic evaluation were made using General Electric Medical Systems Vivid 7 Dimension system and $4 \mathrm{MHz}$ probes (GE Vingmed Ultrasound AS, Horten, Norway).e. All of the measurements were performed based on the American Echocardiography Society standards (23). Images are obtained relative to the axis of the parasternal long axis and apical four chamber (A4C) were used. Measurements were taken from the records stored in the digital media Standard Echocardiography.

Through standard echocardiography, we measured the left ventricular end-diastolic diameter (LVEDD) and the left atrium (LA) and aortic diameter at the parasternal long axis in the M-mode. The left ventricular mass (LVM, g) was calculated using the predefined Devereux and Reichek formula (24). LVM was divided by the body surface area to obtain the left ventricular mass index (LVMI, $\mathrm{g} / \mathrm{m}^{2}$ ).

Measurement of left atrium (LA) and left ventricular (LV) volumes were computed from apical two chamber (A2C) views by Simpson>s method biplane method (25). LA and LV volume index was divided by the body surface area to obtain the $\mathrm{LA}$ and $\mathrm{LV}$ volume $\left(\mathrm{mL} / / \mathrm{m}^{2}\right)$.

Velocity of tricuspid regurgitation (TR) flow was obtained, the maximal systolic pressure gradient between the right atrium and right ventricul $\mathrm{V}$ using the Bernoulli equation $\left(\mathrm{P}=4 \mathrm{~V}^{2}\right)$. The systolic pulmonary artery pressure was calculated by adding the mean right atrium pressure (RAP) to this pressure (26).

\section{Analysis of regional and global myocardial deformation using 2D strain Speckle-Tracking Echocardiography (STE)}

Two-dimensional (2D) strain data were stored in digital format and analyzed offline with the workstation (Echopac, PC 2008, GE, Horten, Norway).

Quality ECG signal and the frame rate is between 40-100 frames/seconds (sn) were recorded in digital format using 2D harmonic image cineloop (A4C view). Effective evaluation of the echocardiographic measurements was used digital recordings (DVD-CD) to enable subsequent investigation.
The analyses were performed using a commercially available computer software program by Echopac software. Sampling volumes were placed using the $2 \mathrm{D}$ strain software under the mitral valves at lateral annulus and septum. The cardiac motion was determined from a user-defined tracing along the endocardial-myocardial border. After manual tracing of the endocardial border in the end-systolic frame of a 2D image and selecting the appropriate wall thickness, the software automatically (speckle tracking) determined six segments for longitudinal function: apical, mid and basal segments in the septum and LV lateral wall from apical views. Data were derived when the values for all six segments were considered acceptable by the software or when a value of any one segment with poor tracking (fewer than two segments) was rejected by the software but tracking of that segment was determined to be acceptable. Obtain the average value after repeated three measurements. Strain parameters of 2D STE-derived systolic and diastolic strain, SR, and the global strain was used in in the assessment of left ventricular function. By using the speckle tracking algorithm, we measured peak systolic (VELsys), early diastolic $\left(\mathrm{VEL}_{\mathrm{E}}\right)$ and late diastolic $\left(\mathrm{VEL}_{\mathrm{A}}\right)$ myocardial velocities, longitudinal peak systolic strain (\%), peak systolic SR (SRsys) $\left(\mathrm{s}^{-1}\right)$, peak early diastolic $\left(\mathrm{SR}_{\mathrm{E}}\right)$ and late diastolic $\left(\mathrm{SR}_{\mathrm{A}}\right) \mathrm{SR}$ at the septal and lateral attachments of the mitral valve in patients with obesity.

\section{Statistical analysis}

The statistical evaluation was executed using the Statistical Package for the Social Sciences (SPSS) software version 12.5 (SPSS Inc.; Chicago, IL, USA). When presenting the results of such categorical data analysis, and percentages, and continuous data were expressed as means \pm standard deviation. The Kolmogorov-Smirnov test was applied to check the distribution of parameters.

The independent $t$ test was used to compare continuous variables in the obese and control groups.. As with correlation is used to analyze the relation between two groups. Pearson's linear correlation coefficient analysis was used to assess the relationship between strain imaging-derived indexes of LV systolic-diastolic functions (global strain, strain, strain rate, etc.) and other parameters (LVM, BMI).

\section{RESULTS}

\section{Clinical and demographic characteristics}

The study sample included 60 obese subjects (Group 1), and 50 healthy subjects were used as controls (Group 2). Clinical and demographic characteristics of the two groups are described in Table 1. Groups were similar with respect to age, sex, pubertal stage, heart rate, and BP. As expected, weight, 
TABLE 1. Demographic characteristics of the obese and control groups

\begin{tabular}{lccc}
\hline & $\begin{array}{c}\text { Group 1 } \\
\text { (Obese group) } \\
\text { (n: 60) }\end{array}$ & $\begin{array}{c}\text { Group 2 } \\
\text { (Control group) } \\
\text { (n: 50) }\end{array}$ & $\begin{array}{c}\text { p } \\
\text { value }\end{array}$ \\
\hline Age (years) & $13.9 \pm 2.3$ & $13.2 \pm 1.8$ & 0.9 \\
Gender & $28 \mathrm{M} / 32 \mathrm{~F}$ & $27 \mathrm{M} / 23 \mathrm{~F}$ & 0.46 \\
(M: male, F: female) & & & \\
BMI (kg/m²) & $30.1 \pm 3.3$ & $19.7 \pm 1.6$ & $<0.001$ \\
Duration of obesity (years) & $3.7 \pm 1.3$ & - & \\
Pubertal stage & $2.7 \pm 0.5$ & $2.6 \pm 0.5$ & 0.36 \\
Systolic blood pressure (BP) & $102.6 \pm 12.5$ & $98.5 \pm 10.3$ & 0.52 \\
(mmHg) & & & \\
Diastolic BP (mmHg) & $66.9 \pm 5.9$ & $64.9 \pm 4.6$ & 0.43 \\
24-h systolic BP (mmHg) & $110.7 \pm 14.6$ & NA & \\
24-h diastolic BP (mmHg) & $61.4 \pm 6.3$ & NA & - \\
Heart rate (bpm) & $82.1 \pm 10.7$ & $79.5 \pm 8.3$ & 0.398 \\
Insulin (mIU/mL) & $12.2 \pm 8.6$ & NA & - \\
Glucose (mmol/L) & $90.1 \pm 7.4$ & NA & \\
HOMA-IR & $2.7 \pm 0.93$ & NA & - \\
\hline
\end{tabular}

Groups were compared by independent $t$ test and $\chi^{2}$ test. Values were expressed as mean \pm standard deviation.

$\mathrm{p}<0.05$ was accepted as statistically significant. $\mathrm{P}$ values less than 0.05 are in bold. BP: blood pressure; bpm: beats per minute

BMI and body fat were elevated in obese subjects $(\mathrm{p}<0.001)$. The mean insulin value was $12.2 \pm 8.6 \mathrm{mIU} / \mathrm{mL}$ and HOMAIR was $2.7 \pm 1.2$ in the obese subgroups. Insulin resistance (HOMA-IR >2.5) was identified in 35 (55.3\%) obese subjects. All patients were already in puberty (Tanner stage $\geq 2$ ). Onset of the average age at obesity was $3.7 \pm 1.3$ years (range, 2-8 years). No pulmonary hypertension was determined in any patient, as measured by CW Doppler echocardiography.

\section{Standard echocardiographic study}

Measurements comparing both groups are shown in Table 2. Global indices of systolic function (left ventricular ejection fraction (LVEF)) were not different between the two groups. As expected, all other M-mode measurements (LVEDD, LA/aortic diameter ratio), LVM, and LVMI were increased $(\mathrm{p}<0.001)$ in obese patients (Group 1) when compared with controls (Group 2). A significant positive correlation was detected between BMI, duration of obesity $(\mathrm{r}=0.527, \mathrm{p}<0.001)$, and the LVM/LVMI $(\mathrm{r}=0.506$, $\mathrm{p}<0.001)$.

\section{D strain speckle tracking analysis}

Longitudinal analysis of the LV myocardium was calculated by STE in obese patients in the A4C view. All of the strain and SR tracings were acceptable for the analysis.
TABLE 2. Standard echocardiographic parameters in the studied population

\begin{tabular}{|c|c|c|c|}
\hline & $\begin{array}{l}\text { Obese group } \\
\text { Group } 1 \\
\text { (n: 60) }\end{array}$ & $\begin{array}{l}\text { Control group } \\
\text { Group } 2 \\
\text { (n: } 50)\end{array}$ & $\begin{array}{c}\mathrm{p} \\
\text { value* }\end{array}$ \\
\hline LVEDD (mm) & $48.5 \pm 3.3$ & $40.9 \pm 3.5$ & $<0.01$ \\
\hline $\mathrm{EF}(\%)$ & $68.6 \pm 2.3$ & $68.1 \pm 3.1$ & 0.37 \\
\hline Left atrium/aortic ratio & $1.42 \pm 0.3$ & $1.2 \pm 0.1$ & $<0.01$ \\
\hline LAEDV (mL) & $29.7 \pm 4.7$ & $20.1 \pm 4.4$ & $<0.01$ \\
\hline LAEDVI $\left(\mathrm{mL} / \mathrm{m}^{2}\right)$ & $16.8 \pm 2.6$ & $14.6 \pm 2.5$ & $<0.01$ \\
\hline LVEDV (mL) & $95.7 \pm 15.2$ & $65.9 \pm 8.2$ & $<0.01$ \\
\hline LVEDVI (mL/m²) & $53.4 \pm 6.6$ & $47.8 \pm 5.9$ & $<0.01$ \\
\hline $\operatorname{LVM}(\mathrm{g})$ & $187.4 \pm 33.1$ & $112.5 \pm 26.0$ & $<0.01$ \\
\hline $\operatorname{LVMI}\left(\mathrm{g} / \mathrm{m}^{2}\right)$ & $98.2 \pm 16.2$ & $79.9 \pm 12.4$ & $<0.01$ \\
\hline $\begin{array}{l}\text { Systolic PAP } \\
\text { (Tricuspid velocity) }\end{array}$ & $16.4 \pm 2.1$ & $19.9 \pm 3.6$ & 0.542 \\
\hline \multicolumn{4}{|c|}{$\begin{array}{l}\text { Groups were compared by independent } t \text { test. Values were expressed as mean stan- } \\
\text { dard deviation. } \\
\text { p }<0.05 \text { was accepted as statistically significant. P values less than } 0.05 \text { are in bold. } \\
\text { LVEDD: left ventricular end-diastolic diameter; EF: ejection fraction; LAEDV: } \\
\text { left atrium end-diastolic volume; LAEDVI: left atrium end-diastolic volume index; } \\
\text { LVEDV: left ventricle end-diastolic volume; LVEDVI: left ventricle end-diastolic } \\
\text { volume index; LVM: left ventricular mass; LVMI: left ventricular mass index; PAP: } \\
\text { pulmonary artery pressure }\end{array}$} \\
\hline
\end{tabular}

There were significant difference between in obese children and controls, with respect to 2D strain longitudinal myocardial deformation properties in the basal, mid and apical segments of the LV walls $(\mathrm{p}<0.001)$ (Tables 3, 4). Peak systolic strain and SR, global strain, and indices of systolic function were significantly reduced in all three segments in patients with obesity. The obese children had a significantly lower LV global strain $(-14.6 \pm 7.34 \%)$ compared to the control subjects $(-20.9 \pm 3.24, \mathrm{p}<0.001)$. Our studies demonstrates a statistically significant difference in obese children; early and late diastolic $\mathrm{SR}$ and early/late $\mathrm{SR}$ ratio $\left(\mathrm{SR}_{\mathrm{E} / \mathrm{A}}\right)$ values using strain imaging of diastolic function when comparing different segments of different LV walls (Tables 3, 4). Left ventricular ejection fraction (LVEF) and regional systolic myocardial velocities were similar between the obese and control groups.

However, by 2D STE, regional strain of both the septal wall (average strain: $-16.0 \pm 3.9 \%$ vs- $21.9 \pm 2.4 \%, \mathrm{p}<0.001$ ) and lateral wall (average strain: $-15.6 \pm 2.3 \%$ vs $-22.9 \pm 3.5 \%$, $\mathrm{p}<0.001$ ); regional SR of both the septal wall (average SRsys: $-0.7 \pm 0.22 \mathrm{~s}^{-1}$ vs $-1.3 \pm 0.32 \mathrm{~s}^{-1}, \mathrm{p}<0.001$ ) and lateral wall (average SRsys: $-0.67 \pm 0.19 \mathrm{~s}^{-1}$ vs $\left.-1.33 \pm 0.31 \mathrm{~s}^{-1}, \mathrm{p}<0.001\right)$; regional $\mathrm{SR}_{\mathrm{E} / \mathrm{A}}$ of both the septal wall (average $\mathrm{SR}_{\mathrm{E} / \mathrm{A}}: 1.8 \pm 0.83 \mathrm{vs}$. $2.2 \pm 0.91$, p: 0.004 ) and lateral wall (average $\mathrm{SR}_{\mathrm{E} / \mathrm{A}:} 1.4 \pm 0.43$ vs. $2.4 \pm 1.21, \mathrm{p}<0.001)$; and global strain $(-14.6 \pm 7.34 \%$ vs $-20.9 \pm 3.24 \%, \mathrm{p}<0.001)$ had significantly lower in the obese group compared with the controls. 
TABLE 3. Left ventricular septal wall longitudinal myocardial velocities, peak systolic and diastolic strain rate $\left(\mathrm{s}^{-1}\right)$, and peak systolic strain $(\%)$ values by speckle tracking method in the studied population (Obese Subject: Group 1, Control: Group 2)

\begin{tabular}{|c|c|c|c|c|}
\hline \multicolumn{2}{|c|}{ Longitudinal function (A4C) } & \multirow{2}{*}{$\begin{array}{c}\text { Group 1 } \\
\text { (n: 60) }\end{array}$} & \multirow{2}{*}{$\begin{array}{c}\text { Group } 2 \\
(\mathrm{n}: 50) \\
6.2 \pm 0.90\end{array}$} & \multirow{2}{*}{$\begin{array}{c}\mathrm{p} \\
\text { value }\end{array}$} \\
\hline VELsys (sep) & basal $(\mathrm{cm} / \mathrm{sn})$ & & & \\
\hline & mid & $3.8 \pm 0.98$ & $3.7 \pm 0.80$ & 0.975 \\
\hline & apical & $1.6 \pm 0.53$ & $1.7 \pm 0.69$ & 0.097 \\
\hline \multirow{3}{*}{$\mathrm{VEL}_{\mathrm{E}}(\mathrm{sep})$} & basal $(\mathrm{cm} / \mathrm{sn})$ & $-8.4 \pm 1.53$ & $-8.4 \pm 1.25$ & 0.893 \\
\hline & mid & $-5.6 \pm 2.07$ & $-6.0 \pm 1.30$ & 0.519 \\
\hline & apical & $-2.1 \pm 0.77$ & $-2.3 \pm 0.92$ & 0.119 \\
\hline \multirow{3}{*}{$\mathrm{VEL}_{\mathrm{A}}(\mathrm{sep})$} & basal $(\mathrm{cm} / \mathrm{sn})$ & $-3.3 \pm 0.89$ & $-3.5 \pm 0.80$ & 0.057 \\
\hline & mid & $-2.0 \pm 0.68$ & $-2.2 \pm 0.67$ & 0.111 \\
\hline & apical & $-0.85 \pm 0.48$ & $-1.0 \pm 0.50$ & 0.051 \\
\hline \multirow[t]{3}{*}{$\mathrm{VEL}_{\mathrm{E} / \mathrm{A}}(\mathrm{sep})$} & basal & $2.8 \pm 1.1$ & $2.6 \pm 0.65$ & 0.060 \\
\hline & mid & $2.7 \pm 1.4$ & $2.8 \pm 0.87$ & 0.778 \\
\hline & apical & $2.9 \pm 2.2$ & $2.7 \pm 1.63$ & 0.320 \\
\hline \multirow[t]{3}{*}{ Strain (sep) } & basal (\%) & $-15.4 \pm 4.39$ & $-20 \pm 3.18$ & $<0.01$ \\
\hline & mid & $-15.8 \pm 5.95$ & $-21 \pm 2.98$ & $<0.01$ \\
\hline & apical & $-16.7 \pm 5.5$ & $-24.5 \pm 4.92$ & $<0.01$ \\
\hline \multirow[t]{3}{*}{ SRsys (sep) } & basal $\left(\mathrm{s}^{-1}\right)$ & $-0.9 \pm 0.23$ & $-1.4 \pm 0.41$ & $<0.01$ \\
\hline & mid & $-0.7 \pm 0.22$ & $-1.3 \pm 0.32$ & $<0.01$ \\
\hline & apical & $-0.5 \pm 0.21$ & $-1.3 \pm 0.44$ & $<0.01$ \\
\hline \multirow[t]{3}{*}{$\mathrm{SR}_{\mathrm{E}}(\mathrm{sep})$} & basal $\left(\mathrm{s}^{-1}\right)$ & $1.28 \pm 0.36$ & $1.4 \pm 0.53$ & 0.032 \\
\hline & mid & $1.38 \pm 0.37$ & $1.5 \pm 0.37$ & 0.081 \\
\hline & apical & $1.36 \pm 0.53$ & $1.7 \pm 0.78$ & 0.009 \\
\hline \multirow[t]{3}{*}{$\mathrm{SR}_{\mathrm{A}}(\mathrm{sep})$} & basal $\left(\mathrm{s}^{-1}\right)$ & $1.06 \pm 0.25$ & $0.8 \pm 0.30$ & $<0.01$ \\
\hline & mid & $1.03 \pm 0.35$ & $0.7 \pm 0.26$ & $<0.01$ \\
\hline & apical & $1.0 \pm 0.39$ & $0.5 \pm 0.3$ & $<0.01$ \\
\hline \multirow[t]{3}{*}{$\mathrm{SR}_{\mathrm{E} / \mathrm{A}}(\mathrm{sep})$} & basal & $1.2 \pm 0.46$ & $1.9 \pm 0.89$ & $<0.01$ \\
\hline & mid & $1.4 \pm 0.52$ & $2.6 \pm 1.52$ & $<0.01$ \\
\hline & apical & $2.6 \pm 1.8$ & $2.7 \pm 1.63$ & 0.320 \\
\hline
\end{tabular}

Groups were compared by independent $t$ test. Values were expressed as mean \pm standard deviation.

$p<0.05$ was accepted as statistically significant. $\mathrm{P}$ values less than 0.05 are in bold Sep: septum; SR: strain rate; VELsys: peak systolic myocardial velocity; $\mathrm{VEL}_{\mathrm{E}}$ : peak early diastolic velocity; $\mathrm{VEL}_{\mathrm{A}}$ : peak late diastolic myocardial velocity; SRsys: peak systolic $\mathrm{SR}\left(\mathrm{s}^{-1}\right) ; \mathrm{SR}_{\mathrm{E}}$ : peak early diastolic $\mathrm{SR} ; \mathrm{SR}_{\mathrm{A}}$ : late diastolic $\mathrm{SR}$

\section{Relationship between obesity and the strain imaging parameters}

Left ventricular longitudinal average peak systolic strain, SR were correlated significantly with LV mass and BMI. No correlation was found between duration of obesity and these strain parameters. The average longitudinal peak systolic strain (\%) and SR correlated significantly with BMI $(r=0.698, r=0.707$, $\mathrm{p}<0.001$, respectively). There was also a significant association between global strain and LVM $(r=0.363, \mathrm{p}<0.01)$. Moreover,
TABLE 4. Left ventricular lateral wall longitudinal myocardial velocities, peak systolic and diastolic strain rate $\left(\mathrm{s}^{-1}\right)$, and peak systolic strain $(\%)$ values by speckle tracking method in the studied population (Obese Subjects: Group 1, Controls: Group 2)

\begin{tabular}{|c|c|c|c|c|}
\hline & & $\begin{array}{c}\text { Group } 1 \\
(\mathrm{n}: 60) \\
\text { Mean } \pm \text { SD }\end{array}$ & $\begin{array}{c}\text { Group } 2 \\
\text { (n: 50) } \\
\text { Mean } \pm \text { SD }\end{array}$ & $\mathrm{p}$ \\
\hline \multirow[t]{3}{*}{ VELsys (lat) } & basal $(\mathrm{cm} / \mathrm{sn})$ & $6.1 \pm 1.57$ & $5.9 \pm 1.51$ & 0.599 \\
\hline & mid & $4.0 \pm 1.32$ & $3.8 \pm 1.4$ & 0.346 \\
\hline & apical & $2.1 \pm 0.86$ & $1.9 \pm 0.82$ & 0.253 \\
\hline \multirow[t]{3}{*}{$\mathrm{VEL}_{\mathrm{E}}$ (lat) } & basal (cm/sn) & $-6.9 \pm 3.3$ & $-7.3 \pm 2.06$ & 0.530 \\
\hline & mid & $-4.4 \pm 1.82$ & $-4.8 \pm 2.02$ & 0.224 \\
\hline & apical & $-2.2 \pm 1.01$ & $-2.4 \pm 1.25$ & 0.068 \\
\hline \multirow[t]{3}{*}{$\mathrm{VEL}_{\mathrm{A}}$ (lat) } & basal (cm/sn) & $-2.9 \pm 0.97$ & $-2.7 \pm 1.23$ & 0.441 \\
\hline & mid & $-1.9 \pm 0.77$ & $-1.8 \pm 0.64$ & 0.636 \\
\hline & apical & $-1.0 \pm 0.59$ & $-0.94 \pm 0.52$ & 0.615 \\
\hline \multicolumn{2}{|c|}{$\mathrm{VEL}_{\mathrm{E} / \mathrm{A}}$ (lat) basal } & $2.4 \pm 1.27$ & $2.6 \pm 1.38$ & 0.870 \\
\hline & mid & $2.4 \pm 1.15$ & $2.7 \pm 1.13$ & 0.216 \\
\hline & apical & $2.9 \pm 2.4$ & $3.1 \pm 2.25$ & 0.958 \\
\hline \multirow[t]{3}{*}{ Strain (lat) } & basal(\%) & $-15.3 \pm 3.2$ & $-21.7 \pm 3.99$ & $<0.01$ \\
\hline & mid & $-15.5 \pm 2.47$ & $-22.0 \pm 4.17$ & $<0.01$ \\
\hline & apical & $-16.1 \pm 3.66$ & $-24.9 \pm 5.37$ & $<0.01$ \\
\hline \multirow[t]{3}{*}{ SRsys (lat) } & basal $\left(\mathrm{s}^{-1}\right)$ & $-0.91 \pm 0.34$ & $-1.58 \pm 0.41$ & $<0.01$ \\
\hline & mid & $-0.67 \pm 0.23$ & $-1.18 \pm 0.54$ & $<0.01$ \\
\hline & apical & $-0.43 \pm 0.20$ & $-1.23 \pm 0.36$ & $<0.01$ \\
\hline \multirow[t]{3}{*}{$\mathrm{SR}_{\mathrm{E}}$ (lat) } & basal $\left(\mathrm{s}^{-1}\right)$ & $1.43 \pm 0.45$ & $1.7 \pm 0.84$ & 0.01 \\
\hline & mid & $1.18 \pm 0.45$ & $1.36 \pm 0.50$ & 0.042 \\
\hline & apical & $1.05 \pm 0.54$ & $1.37 \pm 0.66$ & 0.01 \\
\hline \multirow[t]{3}{*}{$\mathrm{SR}_{\mathrm{A}}$ (lat) } & basal $\left(\mathrm{s}^{-1}\right)$ & $1.10 \pm 0.28$ & $0.80 \pm 0.37$ & $<0.01$ \\
\hline & mid & $0.97 \pm 0.30$ & $0.63 \pm 0.34$ & $<0.01$ \\
\hline & apical & $0.93 \pm 0.37$ & $0.47 \pm 0.31$ & $<0.01$ \\
\hline \multirow[t]{3}{*}{$\mathrm{SR}_{\mathrm{E} / \mathrm{A}}$ (lat) } & basal & $1.34 \pm 0.58$ & $2.60 \pm 1.48$ & $<0.01$ \\
\hline & mid & $1.26 \pm 0.47$ & $2.63 \pm 1.45$ & $<0.01$ \\
\hline & apical & $1.29 \pm 0.61$ & $2.73 \pm 1.93$ & $<0.01$ \\
\hline
\end{tabular}

Groups were compared by independent $t$ test. Values were expressed as mean \pm standard deviation. $\mathrm{p}<0.05$ was accepted as statistically significant. P values less than 0.05 are in bold.

lat: lateral; SR: strain rate; VELsys: peak systolic myocardial velocity; $\mathrm{VEL}_{\mathrm{E}}$ : peak early diastolic velocity; $\mathrm{VEL}_{\mathrm{A}}$ : peak late diastolic myocardial velocity; SRsys: peak systolic SR $\left(\mathrm{s}^{-1}\right) ; \mathrm{SR}_{\mathrm{E}}$ : peak early diastolic $\mathrm{SR} ; \mathrm{SR}_{\mathrm{A}}$ : late diastolic $\mathrm{SR}$

average $\mathrm{LV}$ lateral wall $\mathrm{SR}_{\mathrm{E} / \mathrm{A}}(\mathrm{r}=-0.458, \mathrm{p}<0.001)$ and septum $\mathrm{SR}_{\mathrm{E} / \mathrm{A}}(\mathrm{r}=-0.219, \mathrm{p}=0.022)$ were negatively correlated with BMI.

\section{DISCUSSION}

Cardiovascular risk has been described not only in obese adults but also in obese children and adolescents $(5-8,27)$. 
Recent studies indicate that this trend of subclinical depression in LV function among obese subjects is observed in the pediatric years $(7,13)$. Therefore, LV peak systolic longitudinal strain and SR values were significantly reduced in these patients combined strain imaging studies $(2,8,11,17,18,28)$. The effect of obesity on left ventricular myocardial function has shown an early finding during childhood $(5,7)$.

We analyzed the association between measures of obesity and LV subclinical dysfunction, measured by STE-derived parameters. The results obtained in our study: 1- Left venticular longitudinal peak systolic strain and SR values was significantly lower in obese patients than in normal-weight controls; 2- These strain imaging parameters appear to be related to the severity of obesity and can contribute to increased BMI; 3- Early clinical stage longitudinal strain parameters (peak systolic strain and SR, global strain, diastolic SR) in obese patients may provide the opportunity to assess the regional myocardial function, and aid in monitoring the progression of the disease. Therefore, it is suggested that even young obese patients should be carefully cardiac monitoring in order to detect myocardial damage.

Impaired LV systolic and diastolic function is the first sign of obesity cardiomyopathy and is evident in obese children (12). In this study, the standard echocardiographic evaluation of obese patients (non-hypertensive children), had higher morphological and functional echocardiographic abnormalities, such as larger LA and LV diameters, increased LV enddiastolic volume/index, and LVM/LVMI, despite being in normal range $(5,10,13,28)$. LV dilatation and hypertrophy as a response to sustained, pressure overload and extended wall stress were decreased LV longitudinal function. Among obese children have increased left ventricular mass $(5,7)$. In fact, BMI was the main predictor of LVM, leading to the development of myocardial dysfunction.

Left ventricular hypertrophy secondary to increased mechanical stress can damage the subendocardial myocardial fibers, which is responsible for regional myocardial function $(2,24,28)$. Therefore, increased afterload left ventricular endsystolic wall stress and tension are adversely affected. (28). Left ventricular mass was found to correlate with a decrease in global LV strain by STE, suggesting that the increased mass can lead to incipient ventricular systolic dysfunction in the early stages of obesity, even in the presence of a normal LVEF. Previous studies that systolic function in obese subjects have shown normal $(13,29)$. This may be attributed to the fact that these studies only used parameters to analyze LVEF which are relatively insensitive in detecting incipient preclinical changes in obese patients. In our study, obese patients with preserved LVEF and peak systolic myocardial velocities.

The STE-derived strain parameter is a relatively new parameter that is used to assess systolic and diastolic myocardial function $(11,13,30)$. Obese subjects also had higher risk of a pseudonormalized diastolic pattern. The use of STE-derived parameters is less load-dependent than Doppler flow analysis (6). Up to this time, studies on 2D speckle tracking strain has a limited number of studies in obese children. It is clear that this method is useful in obesity $(7,13,30)$. Previous studies of obesity LV function to show subclinical abnormalities was used color Doppler strain or 2D speckle tracking strain $(7,8$, $11,13,18-20,30)$. Barbosa et al. (7) reported 50 obese children without comorbidities in 2D speckle tracking analysis, a significant reduction in the longitudinal strain association with BMI. In the same study, they found that EF was not different between obese subjects and controls. Similar results has been reported in 21 obese children with lipid abnormalities by Koopman et al. (8). Our study demonstrated that by 2D STE, regional LV systolic and diastolic strain parameters of both the septal and lateral wall and global strain were lower in the obese group compared with the controls (Tables 3, 4). These strain imaging parameters appear to be related to the severity of obesity and can contribute to increased BMI. Furthermore, our results are similar to the previous study of results $(6,7,30)$. Di Salvo et al. (11) Di Salvo et al reported that normotensive obese children have detected reduction in the LV longitudinal myocardial systolic function using color Doppler imaging.

Di Bello et al. (30) evaluate the regional myocardial function in obese adult patients ( $n=48$; mean age, 32.8 years) and showed that systolic strain and SR values were lower in the obese group than the controls, both at the septum and lateral wall level. It was reported by Lorch et al. (2) that decreased diastolic dysfunction in obese children have recorded using the strain parameters (early diastolic $\mathrm{SR}$ and $\mathrm{SR}_{\mathrm{E} / \mathrm{A}}$ ratios ) in the LV septal and lateral walls.

Our study showed that childhood obesity, in the absence of hypertension, is associated with an altered in the longitudinal LV function by STE However, LV longitudinal strain parameters (peak systolic strain and SR, global strain, diastolic SR) using 2D STE were lower in the obese group compared with the controls. There strain parameters are showing LV systolic and diastolic dysfunction obese subjects in early preclinical stage. Furthermore, LV 2D strain parameters for the assessment of regional myocardial dysfunction in obese children may be a new approach to non-invasive method.

There are several limitations in this study. As this is a small observational study has been studied in healthy obese children. We were not study about long-term changes in the myocardium.. Usual limitations about strain, SR, and the angle dependence should be considered. Our study selected patients can be provided at a certain age range cooperation was held in obese children; therewith myocardial velocities associated relatively shows some changes. For patients to be included, measurements of strain had to be adequately visualized to al- 
low for wall. Therefore, we assessed left ventricular longitudinal myocardial function in our study. However, the radial and circumferential strain, intima-media thickness (IMT), and endothelial function can provide additional information in obese children. These parameters would be added to useful data also to be obtained in obese patients.

Ethics Committee Approval: Ethics committee approval was received for this study from the ethics committee of Türkiye Yüksek İhtisas Training and Research Hospital.

Informed Consent: Written informed consent was obtained from the patients' parents who participated in this study.

Peer-review: Externally peer-reviewed.

Author contributions: Concept - A.E.K.; Design - A.E.K.; Supervision - F.A.P.; Resource - Z.A.; Materials - V.N.B.; Data Collection\&/or Processing - İ.E.; Analysis\&/or Interpretation - M.B.O.; Literature Search - Ş.B.; Writing - A.E.K.; Critical Reviews - F.A.P.

Conflict of Interest: No conflict of interest was declared by the authors.

Financial Disclosure: The authors declared that this study has received no financial support.

\section{REFERENCES}

1. Yildirimturk O, Tayyareci Y, Aytekin S.The impact of body mass index on right ventricular systolic functions in normal and mildly obese healthy patients: a velocity vector imaging study. Echocardiography 2011;28:746-52. [CrossRef]

2. Lorch SM, Sharkey A. Myocardial velocity, strain, and strain rate abnormalities in healthy obese children. $J$ Cardiometab Syndr 2007;2:30-4. [CrossRef]

3. Batalli-Këpuska A, Bajraktari G, Zejnullahu M, Azemi M, Shala M, Batalli A, et al. Abnormal systolic and diastolic myocardial function in obese asymptomatic adolescents. Int J Cardiol. 2013;14:S0167-5273. [Epub ahead of print]

4. Ozturk A, Mazicioglu MM, Hatipoglu N, Budak N, Keskin G, Yazlak Z, et al. Reference body mass index curves for Turkish children 6 to 18 years of age. J Pediatr Endocrinol Metab 2008;21:827-36. [CrossRef]

5. Pinnas-Hamiel O,lerner-Geva L, Copperman N, Jacobson MS. Insulin resistance and parental obesity as predictors to response to therapeutic life style change in obesechildren and adolescents 10-18 years old. J Adolesc Health 2008;43:437-43. [CrossRef]

6. Russo C, Jin Z, Homma S, Rundek T, Elkind MS, Sacco RL, et al. Effect of obesity and overweight on left ventricular diastolic function: a community-based study in an elderly cohort. $\mathrm{J} \mathrm{Am}$ Coll Cardiol 2011 Mar 22;57:1368-74. [CrossRef]

7. Barbosa JA, Mota CC, Simões E, Silva AC, Nunes Mdo C, Barbosa MM. Assessing pre-clinical ventricular dysfunction in obese children and adolescents: the value of speckle tracking imaging. Eur Heart J Cardiovasc Imaging 2013;14:882-9. [CrossRef]
8. Koopman LP, McCrindle BW, Slorach C, Chahal N, Hui W, Sarkola $\mathrm{T}$, et al. Interaction between myocardial and vascular changes in obese children: a pilot study. J Am Soc Echocardiogr 2012;25:401-10. [CrossRef]

9. Cole TJ, Bellizzi MC, Flegal KM, Dietz WH. Establishing a standard definition for child overweight and obesity worldwide: international survey. BMJ 2000;320:1240-3. [CrossRef]

10. Movahed MR, Saito Y. Obesity is associated with left atrial enlargement, E/A reversal and left ventricular hypertrophy. Exp Clin Cardiol 2008;13:89-91.

11. Di Salvo G, Pacileo G, Del Giudice EM, Natale F, Limongelli G, Verrengia M, et al. Abnormal myocardial deformation properties in obese, non-hypertensive children: an ambulatory blood pressure monitoring, standard echocardiographic, and strain rate imaging study. Eur Heart J 2006;27:2689-95. [CrossRef]

12. Alpert MA. Obesity cardiomyopathy: pathophysiology and evolution of the clinical syndrome. Am JMed Sci 2001;321:22536. [CrossRef]

13. Barbosa MM, Beleigoli AM, de Fatima Diniz M, Freire CV, Ribeiro AL, Nunes MC.Strain imaging in morbid obesity: insights into subclinical ventricular dysfunction. Clin Cardiol 2011;34:288-93. [CrossRef]

14. Bussadori C, Moreo A, Di Donato M, De Chiara B, Negura D, Dall'Aglio E, et al. A new 2D-based method for myocardial velocity strain and strain rate quantification in a normal adult and paediatric population: assessment of reference values. Cardiovasc Ultrasound 2009;13:7-8.

15. Dogan V, Öcal B, Orun UA, Ozgur S, Y1lmaz O, Keskin M, et al. Strain and strain rate echocardiography findings in children with symptomatic congenital aortic stenosis. Pediatr Cardiol 2013; 34:1152-8. [CrossRef]

16. Lorch SM, Ludomirsky A, Singh GK. Maturational and growthrelated changes in left ventricular longitudinal strain and strain rate measured by two-dimensional speckle tracking echocardiography in healthy pediatric population. J Am Soc Echocardiogr 2008;21:1207-15. [CrossRef]

17. Wong CY, O’Moore-Sullivan T, Leano R, Hukins C, Jenkins C, Marwick TH. Association of subclinical right ventricular dysfunction with obesity. J Am Coll Cardiol 2006;47:611-6. [CrossRef]

18. Wong CY, O’Moore-Sullivan T, Leano R, Byrne N, Beller E, Marwick TH. Alterations of left ventricular myocardial characteristics associated with obesity. Circulation 2004;110:3081-7. [CrossRef]

19. Wong CY, O’Moore-Sullivan T, Fang ZY, Haluska B, Leano R, Marwick TH. Myocardial and vascular dysfunction and exercise capacity in the metabolic syndrome. Am J Cardiol 2005;96:1686-91. [CrossRef]

20. Gong HP, Tan HW, Fang NN, Song T, Li SH, Zhong M, et al. Impaired left ventricular systolic and diastolic function in patients with metabolic syndrome as assessed by strain and strain rate imaging. Diabetes Res Clin Pract 2009;83:300-7. [CrossRef] 
21. Tümer N, Yalçinkaya F, Ince E, Ekim M, Köse K, Cakar N, et al. Blood pressure nomograms for children and adolescents in Turkey. Pediatr Nephrol 1999;13:438-43. [CrossRef]

22. Kurtoğlu S, Hatipoğlu N, Mazıcıoğlu M, Kendirici M, Keskin M, Kondolot M. Insulin resistance in obese children and adolescents: HOMA-IR cut-off levels in the prepubertal and pubertal periods. J Clin Res Pediatr Endocrinol 2010;2:100-6. [CrossRef]

23. Lang RM, Bierig M, Devereux RB, Flachskampf FA, Foster E, Pellikka PA. Recommendations for chamber quantification: a report from the American Society of Echocardiography's Guidelines and Standards Committee and the Chamber Quantification Writing Group, developed in conjunction with the European Association of Echocardiography, a branch of the European Society of Cardiology. J Am Soc Echocardiogr 2005;18:1440-63. [CrossRef]

24. Devereux RB, Reichek N. Echocardiographic determination of left ventricular mass in men: anatomic validation of the method. Circulation 1997;55:13-8.

25. Cain PA, Ahl R, Hedstrom E, Ugander M, Allansdotter-Johnsson A, Friberg P, et al. Age and gender specific normal values of left ventricular mass, volume and function for gradient echo magnetic resonance imaging: a cross sectional study. BMC Med Imaging 2009;9:2. [CrossRef]

26. Hatle L, Angelsan BAJ, Tromsdal A. Noninvasive estimation of pulmonary artery systolic pressure with Doppler ultrasound. $\mathrm{Br}$ Heart J 1981;45:157-65. [CrossRef]

27. Zeybek C, Celebi A, Aktuglu-Zeybek C, Onal H, Yalcin Y, Erdem A, et al. The effect of low-carbohydrate diet on left ventricular diastolic function in obese children. Pediatr Int 2010;52:218-23. [CrossRef]

28. Kosmala W, Wong C, Kuliczkowska J, Leano R, PrzewlockaKosmala M, Marwick TH. Use of body weight and insulin resistance to select obese patients for echocardiographic assessment of subclinical left ventricular dysfunction. Am J Cardiol 2008;101:1334-40. [CrossRef]

29. Crisostomo LL, Araújo LM, Câmara E, Carvalho C, Silva FA, Vieira M, et al. Comparison of left ventricular mass and function in obese versus nonobese women $<40$ years of age. $\mathrm{Am} \mathrm{J}$ Cardiol 1999;84:1127-9. [CrossRef]

30. Di Bello V, Santini F, Di Cori A, Pucci A, Palagi C, Delle Donne $\mathrm{MG}$, et al. Relationship between preclinical abnormalities of global and regional left ventricular function and insulin resistance in severe obesity: a color Doppler imaging study. Int $J$ Obes 2006;30:948-56. [CrossRef] 